\title{
O PENSAMENTO SISTÊMICO COMO FERRAMENTA ORGANIZACIONAL DA GESTÃO DE DESIGN NOS GRUPOS PRODUTIVOS ECONOMICOS SOLIDÁRIOS.
}

\author{
Systemic thinking as a tool of management organizational design group in \\ production solidary economical. \\ Preto, Seila Cibele Sitta; Mestranda; \\ Universidade Federal de Santa Catarina - UFSC \\ cibelesittap@gmail.com
}

Figueiredo, Luiz Fernando Gonçalves de; Doutor;

Universidade Federal de Santa Catarina - UFSC

Iff@cce.ufsc.br

\begin{abstract}
RESUMO
Este artigo visa demonstrar como o pensamento sistêmico utilizado como ferramenta organizacional na gestão de design pode contribuir para os Grupos Produtivos Solidários de um programa de Economia Solidária. Para a coleta de dados foi utilizado à técnica de entrevista qualitativa de profundidade e seus resultados demonstrados, conforme os perfis apresentados. Por meio de uma abordagem sistêmica, utilizam-se etapas do método sistêmico, para a construção de mapas. Tem como resultados parciais uma lista de prioridades onde o design poderá contribuir para as necessidades em curto prazo e prospectando em longo prazo por meio dos três níveis da gestão do design.
\end{abstract}

Palavras chave: pensamento sistêmico; gestão de design; Grupos Produtivos solidários.

\begin{abstract}
This article aims to demonstrate how systems thinking as a tool used in the management of organizational design can contribute to productive groups supportive of a program of the Solidarity Economy. To collect data we used the technique of qualitative depth interviews and the results demonstrated, as the profiles presented. By means of a systemic approach, we use the systemic method steps for the construction of maps. Its results a partial list of priorities where the design can contribute to the needs in the short term and long-term prospecting through the three levels of design management.
\end{abstract}

Keywords: systems thinking, design management, productive groups in solidarity.

\section{INTRODUÇÃO}

A Economia Solidária proporciona uma forma diferente de trabalho e renda dentro de condições de desemprego ou situação de vulnerabilidade social, pois no atual mercado de trabalho a competitividade é grande e excludente, deixando muitas pessoas sem emprego.

A realidade social atual do município de Londrina em estudo possui altos índices de concentração de renda e de desigualdade social, de acordo com o coeficiente Gini $^{1}$ de 0,580. Este estudo demonstrado no documento da $\mathrm{PML}^{2}$ relata "a situação multidimensional de vulnerabilidade social" deste município. (PML, 2010: 3-6).

Diante deste contexto a questão norteadora da pesquisa é: Como a gestão de design pode contribuir com os Grupos Produtivos do Programa Municipal de Economia Solidária de Londrina com melhorias em seu sistema de produção solidária, sustentabilidade econômica, inserção mercadológica 
e a comercialização dos produtos solidários?

Na pesquisa de campo, o método a utilizado será através de diagnósticos com entrevista qualitativa semiestruturadas e ferramentas específicas para levantar as potencialidades e as fragilidades dos Grupos Produtivos, com o intuito de propor melhorias prioritárias de gestão de design aos mesmos.

De acordo com Santos (2005) que trabalhou com as barreiras no trabalho artesanal, algumas fragilidades são frequentes nos Grupos Produtivos da Economia Solidária, dentre as quais se destacam: a falta de planejamento, administração e execução dos produtos; dificuldades dos participantes dos grupos em novos aprendizados; autoestima baixa devido a problemas socioeconômicos; falta de noção do valor cultural do trabalho artesanal; pobreza financeira e de oportunidades; falta de conscientização da própria sociedade no consumo solidário e colaborativo, que serão os itens prioritários para o diagnostico.

Esta pesquisa então se justifica pela contribuição da gestão de design no contexto da coordenação e articulação dos recursos existentes em uma organização de produtos que possuam identidade, diferenciação e sustentabilidade em sua produção, além do aperfeiçoamento, fortalecimento e desenvolvimento dos Grupos Produtivos, estimulando este setor que se apresenta como promissor, tanto em geração de trabalho e renda, como qualidade em produtos.

\section{Economia Solidária e Grupos Produtivos}

Nos últimos anos a Economia Solidária apresenta-se, como uma inovadora alternativa de geração de trabalho e renda e uma resposta a favor da inclusão social, segundo informações declaradas pelo $\mathrm{MTE}^{3}$, em 2011. Inclui uma diversidade de práticas econômicas e sociais organizadas sob a forma de cooperativas, associações, clubes de troca, empresas autogestionárias, redes de cooperação, entre outras, que realizam atividades de produção de bens, prestação de serviços, finanças solidárias, trocas, comércio justo e consumo solidário. (MTE, 2011a) ${ }^{4}$.

O MTE define a Economia Solidária como:

[...] um jeito diferente de produzir, vender, comprar e trocar o que é preciso para viver. Sem explorar os outros, sem querer levar vantagem, sem destruir o ambiente. Cooperando, fortalecendo o grupo, cada um pensando no bem de todos e no próprio bem. (MTE, 2011b)

A Prefeitura da cidade de Londrina - PR, que promove o Programa Municipal de Economia Solidária na cidade, tem como definição:

Economia Solidária é uma forma diferente de trabalhar, produzir, comercializar e consumir. É o conjunto de atividades econômicas de produção, distribuição, consumo, poupança e crédito organizadas e realizadas solidáriamente de forma coletiva e autogestionária. Além da cooperação, a Economia Solidária trabalha por intermédio de Oficinas Solidárias, Assessoria, capacitação técnica e de gestão e de investimento solidário. (PMESL, 2011)..$^{5}$

Para Arroyo (2006, p.65) pensar em Economia Solidária é pensar grande, aplicada ao local/e ou território, no intuito de reverter à lógica da desigualdade, por meio de condutas humanas e éticas para um modelo de novo padrão civilizatório. Pois a Economia Solidária tem princípios a serem seguidos. Estes princípios no Brasil são a cooperação, a solidariedade, a autogestão e a atividade econômica. Cada princípio tem sua explicação, segundo informações declaradas pelo Programa Municipal de Economia Solidária de Londrina.

- Atividade Econômica: "A Economia Solidária constitui-se numa atividade econômica, porque envolve produção, comercialização, consumo e tudo isso se refere a trabalho e renda".

- Autogestão: Trabalho coletivo em que todos os trabalhadores participam de todo o 
O pensamento sistêmico como ferramenta organizacional da gestão de design nos grupos produtivos ... solidários.

processo de gestão e produção de trabalho e renda, desde o planejamento estratégico, a produção, a comercialização, o compartilhamento das tarefas, nas ideias, nas decisões, e sempre dividindo a renda de forma igual.

- Cooperação: a "cooperação acontece quando um grupo contribui com suas energias para a realização de tarefas de interesse comum". A forma de organização dos empreendimentos econômicos solidários é por meio de cooperativas que tem como significado, trabalhar junto.

- Solidariedade: A solidariedade deve passar por todas as ações na Economia Solidária, por meio da inclusão social nos benefícios e ser praticada a serviço da coletividade.

A Economia Solidária é incentivada em âmbito nacional. A SENAES ${ }^{6}$, secretaria que foi criada no Ministério do Trabalho e Emprego com a publicação da Lei no 10.683, de 28 de maio de 2003 e instituída pelo Decreto $\mathrm{n}^{\circ} 4.764$, de 24 de junho de 2003, com o objetivo de "viabilizar e coordenar atividades de apoio à Economia Solidária em todo o território nacional, visando à geração de trabalho e renda, à inclusão social e à promoção do desenvolvimento justo e solidário". (MTE, 2011). ${ }^{7}$

Em consulta a lei no 10.523, "o Programa Municipal de Economia Solidária constituiu-se como uma ação intersetorial da Prefeitura Municipal de Londrina com a participação das diversas políticas setoriais". O Programa estará vinculado à estrutura administrativa da Secretaria Municipal de Assistência Social e será coordenado por esta. (LEI No 10.523, DE 28 DE AGOSTO DE 2008). ${ }^{8}$

O Programa Municipal de Economia Solidária está inserido na cidade através da prefeitura municipal, que possui internamente a secretaria de assistencia social, a qual oferece serviços eixos, sendo o de proteção social básica, o serviço que está inserido a inclusão produtiva e que está inserida a Economia Solidária.

O Programa Municipal de Economia Solidária é um dos resultados das ações do Programa Londrina Fome Zero de 2003. São as primeiras atividades da Economia Solidária desenvolvidas pelo PPM" ${ }^{9}$ em um de seus eixos: Geração de Renda e Capacitação Profissional. "Tais realizações indicaram avanços, dificuldades e desafios, e ensejaram na implantação do programa e posteriormente em sua criação, por meio da Lei Municipal no 10.523, de 28 de agosto de 2008".

Para a implantação do programa parte-se do respeito a alguns princípios que permeiam a organização, segundo os dados declarados pelo Programa Municipal de Economia Solidária.

Articulação e Integração, que administra em âmbito interno e externo as entidades de apoio à Economia Solidária, otimizando ações intersetoriais aos envolvidos no programa.

Protagonismo dos empreendedores solidários, que trabalham o empreendedorismo dos grupos na parte de produção, comercialização e consumos dos produtos e serviços solidários.

Transparente, ético e participativo, quanto às atividades executadas e recursos utilizados e a própria construção do programa junto da prefeitura e parceiros.

Foco no coletivo e matricialidade familiar, reforçando a convivência familiar e comunitária, resgatando identidade e sentimentos de pertencimento.

Desenvolvimento Local, voltando o olhar para as necessidades e o potencial produtivo e de consumo, valorizando as capacidades locais.

Linhas de ação, que trabalham com finanças solidárias, Educação para o consumo ético, justo e solidário; Capacitação conceitual, técnica e de gestão; Assessoria aos empreendimentos econômicos solidários; Apoio à implementação da rede solidária de produção, comercialização e consumo.

Portanto, o Programa Municipal de Economia Solidária de Londrina oferece capacitação dos integrantes dos Grupos Produtivos por meio de oficinas, assessorias, trabalho de inclusão social e gestão dos empreendimentos solidários.

Para tanto, são esclarecidos alguns conceitos e formas de atuação da Economia Solidária para com seus Grupos Produtivos, enquanto oportuniza geração de trabalho e renda, além da inclusão social.

\section{Pensamento Sistêmico}

O pensamento sistêmico é uma nova forma de estrutura conceitual ou metalinguagem em 
Preto, Seila Cibele Sitta; Figueiredo, Luiz Fernando Gonçalves de

desenvolvimento, com o objetivo de lidar com situações que requerem explicações baseadas na inter-relação. Segundo Seleme (2006, p.49) é utilizado em diversas áreas de investigação, tais como a biologia, a cibernética, engenharia de sistemas, administração, economia entre vária outras. Relata ainda que a ideia central do pensamento sistêmico é a organização sistêmica ou estrutura sistêmica. Esta delimita um padrão de interações de forma explicativa e não estática.

O pensamento sistêmico está interessado nas características essenciais do todo integrado e dinâmico, características essas que não estão em absoluto nas partes, mas nos relacionamentos dinâmicos entre elas, entre ela e o todo e entre o todo e outros todos. (SELEME, 2006, P.44).

O pensamento sistêmico pressupõe pensar em processos, os quais configuram a existência do todo, e é por meio desses processos que se realiza a existência de uma situação ou fenômeno a ser investigado, que busca entender os padrões e processos da organização, para possibilitar a renovação e reorganização da situação, além de melhorar a capacidade de aprendizagem.

De acordo com Capra (2006, p. 260), o pensamento sistêmico vê o mundo em termos de relações e integração. Os sistemas são totalidades integradas, cujas propriedades não podem ser reduzidas as unidades menores. Em vez de se concentrar nos elementos ou substâncias básicas, a abordagem sistêmica enfatiza princípios básicos de organização.

Para Bertalanffy (2009) é necessário estudar os sistemas globalmente, de forma a envolver todas as suas interdependências, pois cada um dos elementos, ao serem reunidos para constituir uma unidade funcional maior, desenvolvem qualidades que não se encontram em seus componentes isolados. Ludwig von Bertalanffy foi o primeiro autor a introduzir a ideia de teoria geral dos sistemas e dizer que o conceito de sistema constitui um novo "paradigma", [...] uma "nova filosofia da natureza" [...] e que a teoria geral dos sistemas é uma ciência geral da totalidade, sendo então "uma investigação científica de "conjuntos" e "totalidades" [...]". (BERTALANFFY, 2009, p.14)

Já Martins e Theóphilo (2009, p.42) acreditam que pensar sistemicamente é administrar, e "administrar é tratar da manutenção de sistemas, levá-los ao funcionamento mais racional e produtivo possível".

Para compreender melhor como pensar sistemicamente, tem-se o método sistêmico, que é um conjunto de passos que permite o entendimento de uma situação de transformação organizacional e a construção de ações sustentáveis, de acordo com Seleme (2006, p.95-96), são eles:

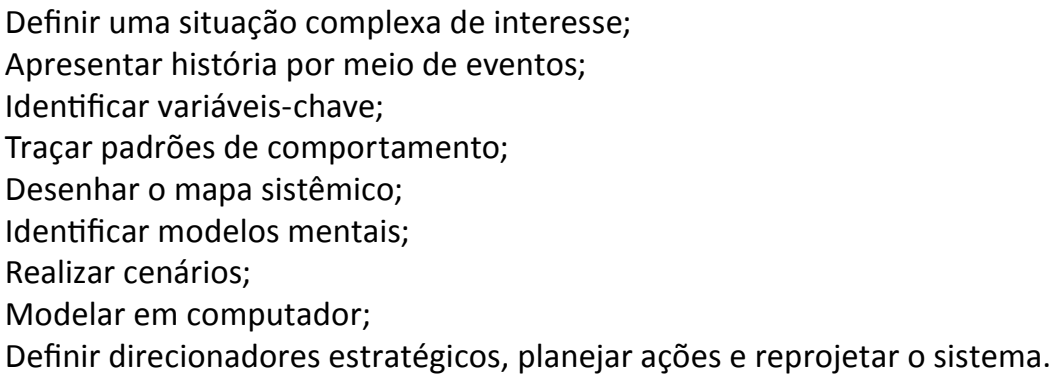

O mapa sistêmico, um dos passos do método sistêmico, tem como função a construção de uma estrutura sistêmica que determina "os padrões de comportamento da organização [ou comunidade] por meio da identificação das relações causais entre fatores e sobre a situação de interesse" (ANDRADE, 2006, p. 112).

Por meio dos resultados do pensamento sistêmico apoiado pelo método sistêmico, a gestão de design poderá contribuir na melhoria da situação organizacional dos Grupos Produtivos solidários e do Programa Municipal de Economia Solidária, desde o diagnóstico até a aplicação das ações.

O processo sistêmico da gestão trabalha o todo como

Atividades colaborativas contínuas de reflexão e ação. Gestores [...] percebem as 
interconexões dos objetos e ações [...] percepções e entendimento compartilhados emergem de toda a organização. Mínima especificação critica. Auto-organização e autocontrole.

E nos processos "atua no nível mais profundo dos processos estruturantes. Reconhece e promove a auto-organização criativa e alinhada no nível do processo". Nos relacionamentos "percebe a interconexão de problemas e da teia maior que os sustentam". (SELEME, 2006, p.387).

Portanto, a gestão de design pode ajudar os Grupos Produtivos a pensarem conjuntamente nos diversos saberes de uma organização, em seus desdobramentos futuros, em seus valores, conflitos e necessidades, para que tais estratégias dessa gestão gerem mudanças e transformações, torneando-se um sistema produto-serviço, que devem ser acompanhadas por táticas que coordenarão as operações de design na gestão de design conceituada no capítulo a seguir.

\section{Conceitos de Gestão de Design}

Esta pesquisa busca o entendimento na Gestão do Design entre os três níveis, o operacional, o tático e o estratégico. Para tanto, torna-se necessário fundamentar-se em conceitos da Gestão de Design como mostra tabela abaixo com a exposição de várias definições.

Quadro 01 - Conceitos e definições de Gestão de Design.

\begin{tabular}{|c|c|}
\hline Conceitos & Autores \\
\hline $\begin{array}{l}\text { "a Gestão de Design é a administração das atividades de design com base nos objetivos da } \\
\text { empresa em curto, médio e longo prazo [...] auxilia a organização a aumentar sua eficiência, } \\
\text { manter-se competitiva e diferenciar seus produtos e serviços". }\end{array}$ & MARTINS; MERINO, 2011, p.21 \\
\hline $\begin{array}{l}\text { "A Gestão de Design implica na concatenação do gerenciamento, coordenação, planejamento, } \\
\text { projeto e programação das atividades de design, em qualquer uma das suas áreas em empresas } \\
\text { ou instituições [...] representa a capacidade de se ter uma visão conjunta de um plano de ação } \\
\text { que compreende processos, projetos e tarefas de ideias que se manifestam por intermédio da } \\
\text { linguagem e da estética, definindo a qualidade dos produtos e da comunicação da empresa, } \\
\text { intensificando o gerenciamento de seus recursos criativos e competências". }\end{array}$ & FAGGIANI, 2006, p.115 \\
\hline $\begin{array}{l}\text { "conjunto de técnicas de géstion empresarial dirigidas a maximização menor custo posible, la } \\
\text { competitividade que obtiene la empresa por la incorporación y utilización del desenho industrial } \\
\text { como instrumento de su estrategia empresarial". }\end{array}$ & GIMENO, 2000, p.25 \\
\hline $\begin{array}{l}\text { "A gestão do design possui a função de "planejar e coordenar as estratégias correspondentes } \\
\text { aos objetivos e valores da empresa, motivar os empregados e controlar os trabalhos, } \\
\text { assegurando que cumpram com os objetivos, com os prazos e os custos planejados"”. }\end{array}$ & WOLF, 1998, p.18 \\
\hline $\begin{array}{l}\text { "conjunto de atividades de diagnostico, coordenação, negociação e Design, que pode ser } \\
\text { desenvolvida tanto na atividade de consultoria externa como no âmbito da organização, } \\
\text { interagindo com os setores responsáveis pela produção, programação econômico-financeira e } \\
\text { comercialização, permitindo sua participação ativa nas decisões dos produtos". }\end{array}$ & $\begin{array}{l}\text { AVEDAÑO, } 2003 \text { apud MARTINS; } \\
\text { MERINO, } \\
\text { 2011, p.147 }\end{array}$ \\
\hline $\begin{array}{l}\text { "ela consiste em integrar necessidades tecnológicas, sociais e econômicas, biológicas e efeitos } \\
\text { psicológicos de materiais, forma, cor, volume e espaço. Proporciona a percepção do conjunto e } \\
\text { do detalhe, do imediato e do final". }\end{array}$ & $\begin{array}{c}\text { MERINO, } 2003 \text { apud MARTINS; MERINO, } \\
\text { 2011, p.147 }\end{array}$ \\
\hline $\begin{array}{l}\text { "é a atividade macro das estratégias dos designers (ou grupos interdisciplinares), com o poder } \\
\text { decisório em uma organização, estruturada em moldar o perfil da empresa, produtos e/ou } \\
\text { serviços [...]". }\end{array}$ & $\begin{array}{c}\text { SOARES, } 2002 \text { apud MARTINS; MERINO, } \\
\text { 2011, p.148 }\end{array}$ \\
\hline
\end{tabular}

Fonte: própria, 2011.

O Manual de Gestão do Design (1997) e Bahiana (1998), não focam nos três níveis da gestão de design, o operacional, tático e estratégico, porém relatam o estratégico, sendo este relevante para a pesquisa e dizem que:

Tem como função partindo da administração ou nível estratégico aspectos de diagnosticar a situação da empresa e de seus produtos, definir futuros processos 
produtivos, produtos e mercados, detectar os pontos fortes e fracos da empresa e de integrar o desenvolvimento dos produtos com as funções de produção, marketing e comunicação da empresa. (MANUAL DE GESTÃO DO DESIGN, 1997).

O potencial da gestão estratégica deve ser incorporado ao processo de produção desde a concepção da estratégia da empresa, passando pela concepção do produto e em todas as fases do ciclo de vida, integrando com outras áreas, e sob todos os aspectos em que se possa ser aplicado como marca, identidade visual, embalagem do produto, embalagem de transporte, comunicação, material de apoio de vendas, arquitetura, entre outras, ao que se chama Gestão de Design. (BAHIANA, 1998 apud MARTINS; MERINO, 2011, p.146).

No entanto, clarifica-se sobre alguns conceitos e definições da Gestão de Design. Pesquisam-se então posteriormente seus níveis, sendo estes: o nível operacional, o nível tático e o nível estratégico.

\section{Níveis da Gestão de Design}

Por ser uma atividade multidisciplinar, a gestão de design pode trabalhar em diversos ambientes, mostrando as potencialidades do Design em conjunto de outras áreas do conhecimento. Martins; Merino (2011) diz que uma das características da gestão de design é a identificação e a comunicação pelos caminhos do design na construção de estratégias. Mozota (2011) complementa que a integração da gestão de design na empresa deve ser em nível operacional de projeto, organizacional ou tático (função) ou estratégico (missão), conforme figura abaixo.

\begin{tabular}{|c|c|c|}
\hline AÇÃO DE DESIGN & FUNÇÃO DE DESIGN & VISÃO DE DESIGN \\
\hline Valor diferenciador do design & Valor coordenador do design & Valor transformador do design \\
\hline $\begin{array}{l}\text { O design é uma competência eco- } \\
\text { nômica que muda as atividades } \\
\text { primárias da cadeia de valor }\end{array}$ & $\begin{array}{l}\text { O design é uma competência } \\
\text { administrativa que muda as } \\
\text { atividades de apoio na cadeia } \\
\text { de valor }\end{array}$ & $\begin{array}{l}\text { O design é uma competência } \\
\text { central que atua na cadeia de va- } \\
\text { lor do setor e a visão da indústria }\end{array}$ \\
\hline Marketing & Estrutura & Estratégia \\
\hline Produção & Gestão da tecnologia & Gestão de conhecimento \\
\hline Comunicação & Gestão da inovação & Gestão de rede \\
\hline Gestão operacional do design & Gestão funcional do design & Gestão estratégica do design \\
\hline
\end{tabular}

Fonte: Adaptado de Mozota, 2011, p.310

Karjalainen (apud PEREIRA et al, 2002, p.2) apresenta fatores aos níveis da gestão de design estratégico, tático e operacional:

Nível estratégico: fatores ambientais (tendências de mercado, tendências de design, legislação, padrões); manifestações do design (identidade corporativa, padrões de design corporativo, produtos, ambientes, comportamentos, comunicações); fatores internos (estratégias e controle do design corporativo, compreensão do design e desenvolvimento de habilidades para gestão de design, integração, centralização, responsabilidade pelo design, elaboração e introdução de sistemas para gestão de design, avaliação dos investimentos em design, seu impacto e sua contribuição para a atuação da organização).

Nível tático: recursos para o design (humanos, físicos, internos, externos); habilidades para o design; core competencies; treinamento; descrição dos processos, normas e procedimentos para a 
O pensamento sistêmico como ferramenta organizacional da gestão de design nos grupos produtivos ... solidários.

gestão de design; localização, serviços e objetivos da equipe responsável pelo design.

Nível operacional: natureza dos processos e projetos de design; propostas; relacionamento entre gestão e equipe de design do projeto; seleção dos integrantes da equipe; documentação e sistemas de controle; implementação das soluções; avaliação dos projetos.

Martins e Merino (2011, p.152) diz que a gestão de design deve ser adotada pelas empresas para que não haja diferença entre a imagem que transmite e a que pretende transmitir. Para que esse fato não aconteça devem ser trabalhados paralelamente os processos operacionais e estratégicos da empresa. A gestão de design estratégica e operacional tem como função a definição de objetivos e valores da empresa (missão), o desenvolvimento de uma estratégia baseada na missão, junto de sua execução e organização e a coordenação e controle do processo de produção e do resultado.

Desta forma a gestão de design pode contribuir com os Grupos Produtivos nos três níveis, alavancando tais grupos a inserção e exposição mercadológica, ao aprimoramento e qualidade de novos produtos, além de fortalecer a imagem da Economia Solidária.

\section{Metodologia}

Nesta investigação utilizou-se como estratégia de pesquisa a abordagem sistêmica e como técnica algumas das etapas do método sistêmico de acordo com Seleme (2009) e apoiada na entrevista qualitativa de profundidade segundo Bauer e Gaskell (2003), com o intuito de desenvolver um diagnóstico que será utilizado na gestão de design por meio dos níveis estratégicos, operacionais e táticos direcionadas aos Grupos Produtivos solidários e ao sistema atual de gestão do Programa Municipal de Economia Solidária.

Para tanto, neste estudo estão sendo acompanhados quatro Grupos Produtivos, sendo estes, um de cada segmento mercadológico interno do Programa Municipal de Economia Solidária de Londrina, os quais atualmente se dividem em artesanato, alimentação, vestuário e prestação de serviços.

Para cada grupo em particular foi aplicada à entrevista qualitativa de profundidade, que tem como objetivo a explicitação mais direta sobre o assunto em questão.

Para a aplicação da entrevista, anteriormente foi realizado um roteiro para obter conhecimento sobre os aspectos mais relevantes dos Grupos Produtivos. Neste roteiro foram questionados sobre os aspectos de identificação do empreendimento (de que forma eles expressam a identidade e como acham que podem ser identificados), sobre o produto e o mercado (falam sobre o produto de forma geral e o mercado que estão inseridos), sobre o cliente e formas de divulgação, (tanto dos produtos quanto do empreendimento), aspectos relacionados à gestão (de qual forma gerem o empreendimento e quais as dificuldades encontradas), sobre a qualidade dos produtos, (acabamentos, processo produtivo, matéria prima entre outros), sobre a organização e estrutura física do empreendimento, (de acordo com os princípios da Economia Solidária e equipamentos necessários para o desenvolvimento e crescimento do grupo), sobre capacitação, (tanto ofertado pelo programa, como busca externa pelos grupos), sobre aspectos de comercialização dos produtos, (como expor o produto, de que forma abordar o cliente, preço justo) e sobre a própria disseminação do que é a Economia Solidária (como chega ao projeto municipal assistencial).

Estes são aspectos que todos os grupos precisam compreender e saber explicar, porém ainda existe muita dificuldade. E por meio da entrevista, pretende-se classificar e mensurar o desenvolvimento e os problemas de cada grupo produtivo, resultando em perfis que classificarão cada aspecto em nível alto, médio ou baixo.

Segue abaixo o perfil de cada grupo produtivo, classificado de acordo com as informações coletadas na entrevista qualitativa de profundidade, que foram gravadas e posteriormente transcritas para que pudessem serem melhor interpretadas, mensuradas e representadas pelos perfis de cada grupo conforme mostra o gráfico abaixo. 
Preto, Seila Cibele Sitta; Figueiredo, Luiz Fernando Gonçalves de

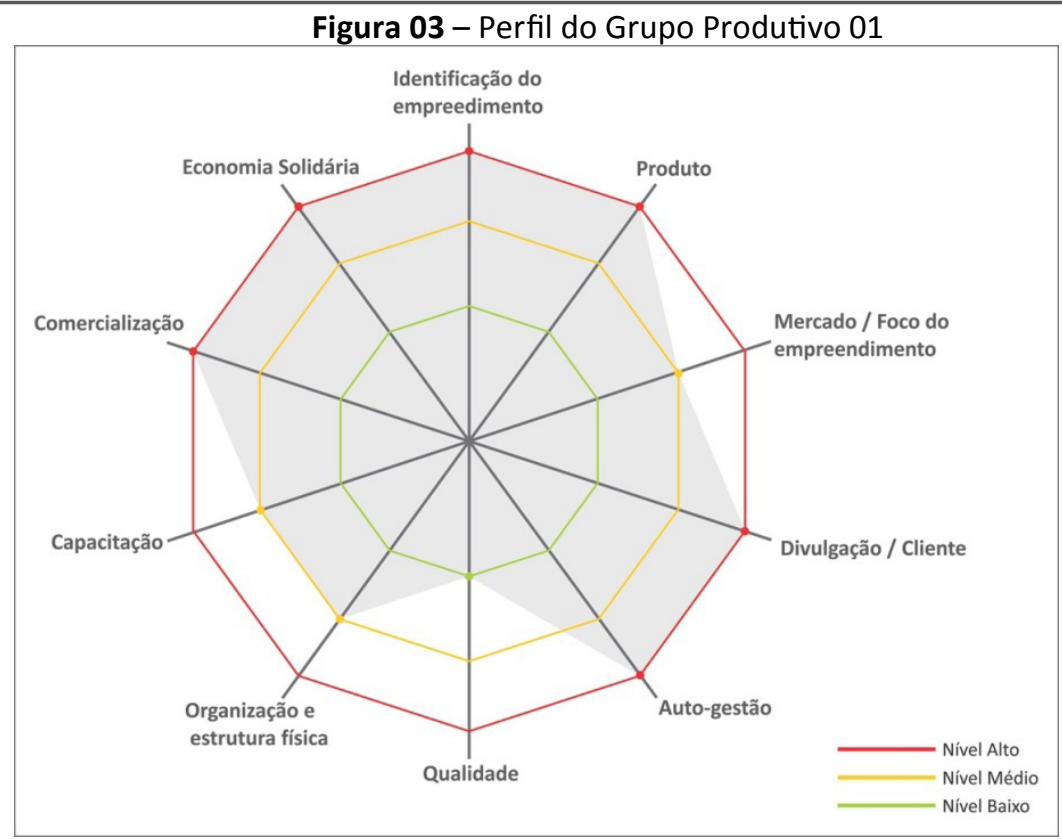

Fonte: Própria, 2012.

No perfil do Grupo Produtivo 01, mostra os aspectos que foram classificados como nível alto, sendo estes: a identificação do empreendimento, o produto, a divulgação/cliente, a autogestão, a comercialização e a Economia Solidária. Já em nível médio foram classificados os seguintes aspectos: mercado/foco do empreendimento, a organização e estrutura física e a capacitação. E em nível baixo exclusivamente a qualidade.

Figura 04 - Perfil do Grupo Produtivo 02

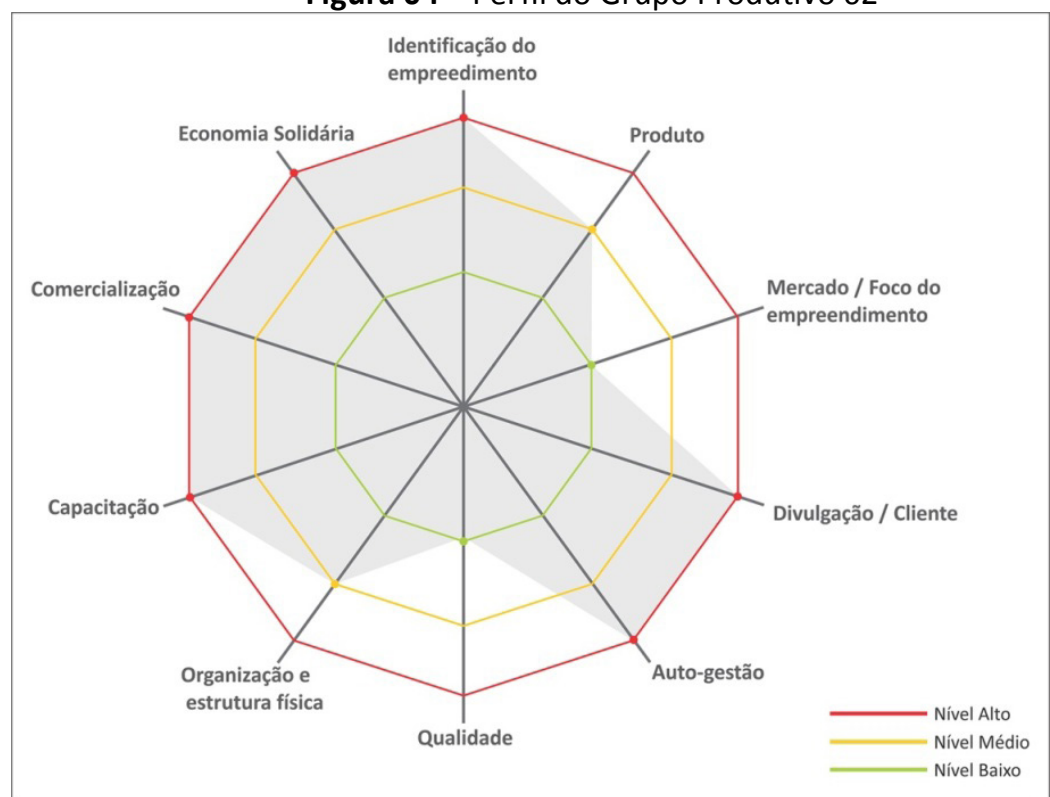

Fonte: Própria, 2012.

No perfil do Grupo Produtivo 02, mostra os aspectos que foram classificados como nível alto, sendo estes: a identificação do empreendimento, a divulgação/cliente, a autogestão, a capacitação, a comercialização e a Economia Solidária. Já em nível médio foram classificados apenas os aspectos produto e organização e estrutura física. E em nível baixo os aspectos mercado/foco do empreendimento 
e a qualidade.

Figura 05 - Perfil do Grupo Produtivo 03

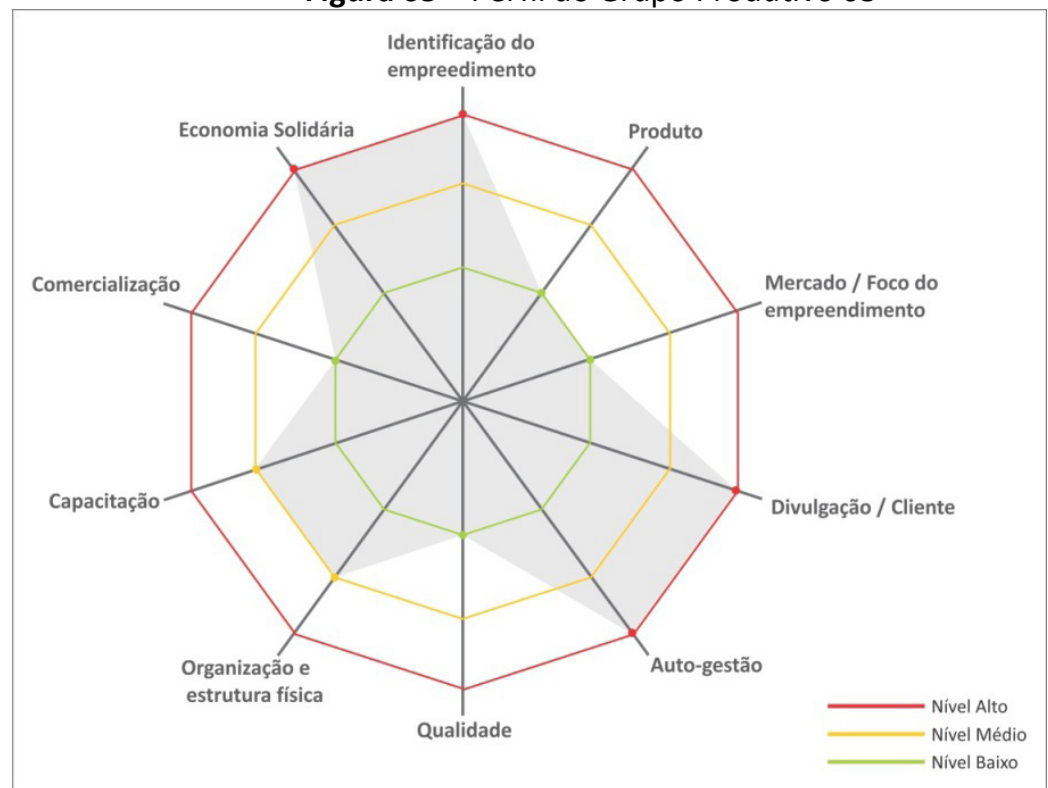

Fonte: Própria, 2012.

No perfil do Grupo Produtivo 03, mostra os aspectos que foram classificados como nível alto, sendo estes: a identificação do empreendimento, a divulgação/cliente, a autogestão e a Economia Solidária. Já em nível médio foram classificados apenas os aspectos organização e estrutura física e capacitação. E em nível baixo os aspectos produto, mercado/foco do empreendimento, qualidade e comercialização.

Figura 06 - Perfil do Grupo Produtivo 04

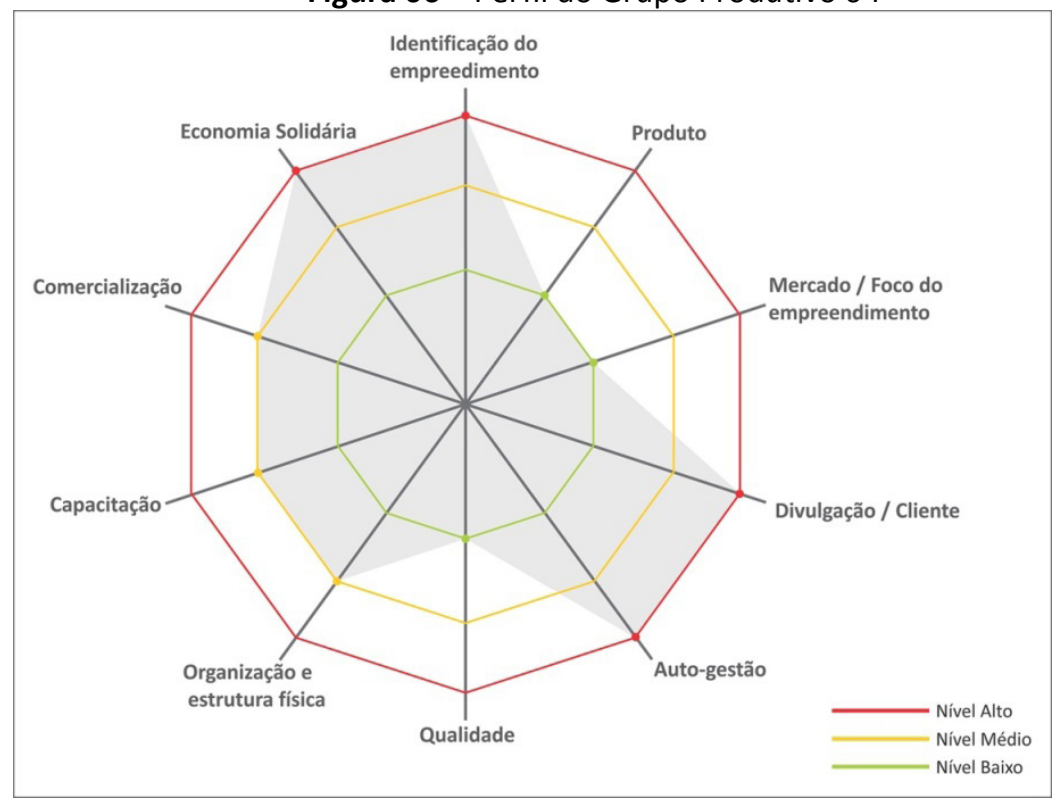

Fonte: Própria, 2012.

No perfil do Grupo Produtivo 04, mostra os aspectos que foram classificados como nível alto, sendo estes: a identificação do empreendimento, a divulgação/cliente, a autogestão e a Economia Solidária. Já em nível médio foram classificados apenas os aspectos organização e estrutura física, capacitação e comercialização. E em nível baixo os aspectos produto, mercado/foco do empreendimento 
e qualidade.

Segue abaixo tabela com os resultados dos perfis dos Grupos Produtivos para visualizar os aspectos mais e menos problemáticos para que a gestão de design possa trabalhar ações entre seus níveis.

\begin{tabular}{|l|c|c|c|}
\hline \multicolumn{3}{|l|}{ Tabela 01 - Resultados dos perfis dos Grupos Produtivos. } \\
\hline ASPECTOS & ALTO & MEDIO & BAIXO \\
\hline Identificação do Empreendimento & 1234 & & \\
\hline Produto & 1 & 2 & 34 \\
\hline Mercado / Foco do Empreendimento & & 1 & 234 \\
\hline Divulgação/Cliente & 1234 & & \\
\hline Gestão & 1234 & & \\
\hline Qualidade & & & 1234 \\
\hline Organização e Estrutura Física & & 1234 & \\
\hline Capacitação & 2 & 134 & \\
\hline Comercialização & 12 & 4 & 3 \\
\hline Economia Solidária & 1234 & & \\
\hline
\end{tabular}

Fonte: própria, 2012.

Todos os Grupos Produtivos acompanhados consideram que possuem nível alto de problemas em relação aos aspectos de identificação do empreendimento, divulgação/cliente, gestão e Economia Solidária, o que acaba anulando toda a comunicação, não gerando disseminação tanto dos grupos e de seu trabalho quanto do programa de Economia Solidária em relação à sociedade.

Todos os grupos possuem nível médio em organização e estrutura física e alguns em capacitação, neste caso um planejamento é essencial para conquista de novas estruturas e a capacitação um investimento para melhorias e inovações ao grupo produtivo e seu processo produtivo.

Já em nível baixo de problemas, somente o aspecto qualidade é pertinente a todos os grupos e o aspecto mercado/foco do empreendimento somente para alguns. Neste ponto, facilita a divulgação e comunicação da marca não apenas como fator de identificação, mas como valor ao produto de acordo com sua origem e forma de produção artesanal e exclusiva.

Portanto, para que os Grupos Produtivos possam expor seus produtos e disseminar na sociedade o trabalho artesanal e a oportunidade de geração de trabalho e renda, que o programa de Economia Solidária oferece, é necessário pensar em algumas ações prioritárias de baixo custo, ou isento que proporcionem condições de aplicações e implantação ainda em andamento nos Grupos Produtivos.

Para tanto, foi desenvolvida uma lista de prioridades de acordo com os resultados dos perfis, que corroboram com a construção de um mapa sistêmico do atual processo de gestão encontrado no qual detecta-se as partes que possuem dificuldades em se reestruturar e assim equilibrar o sistema, conforme finalidade do pensamento e método sistêmico.

\section{Resultados}

Utilizando superficialmente algumas das etapas do método sistêmico, tem-se abaixo um fluxograma de processo e em construção futura, um mapa sistêmico indicado pela figura - 02, o qual é explicitado às etapas da atual gestão no Programa Municipal de Economia Solidária (formação e acompanhamento), ainda sem suas conexões e orientações do macroprocesso. 
O pensamento sistêmico como ferramenta organizacional da gestão de design nos grupos produtivos ... solidários.

Figura 02 - Fluxograma de Processos da Gestão atual da Economia Solidária da cidade de Londrina.

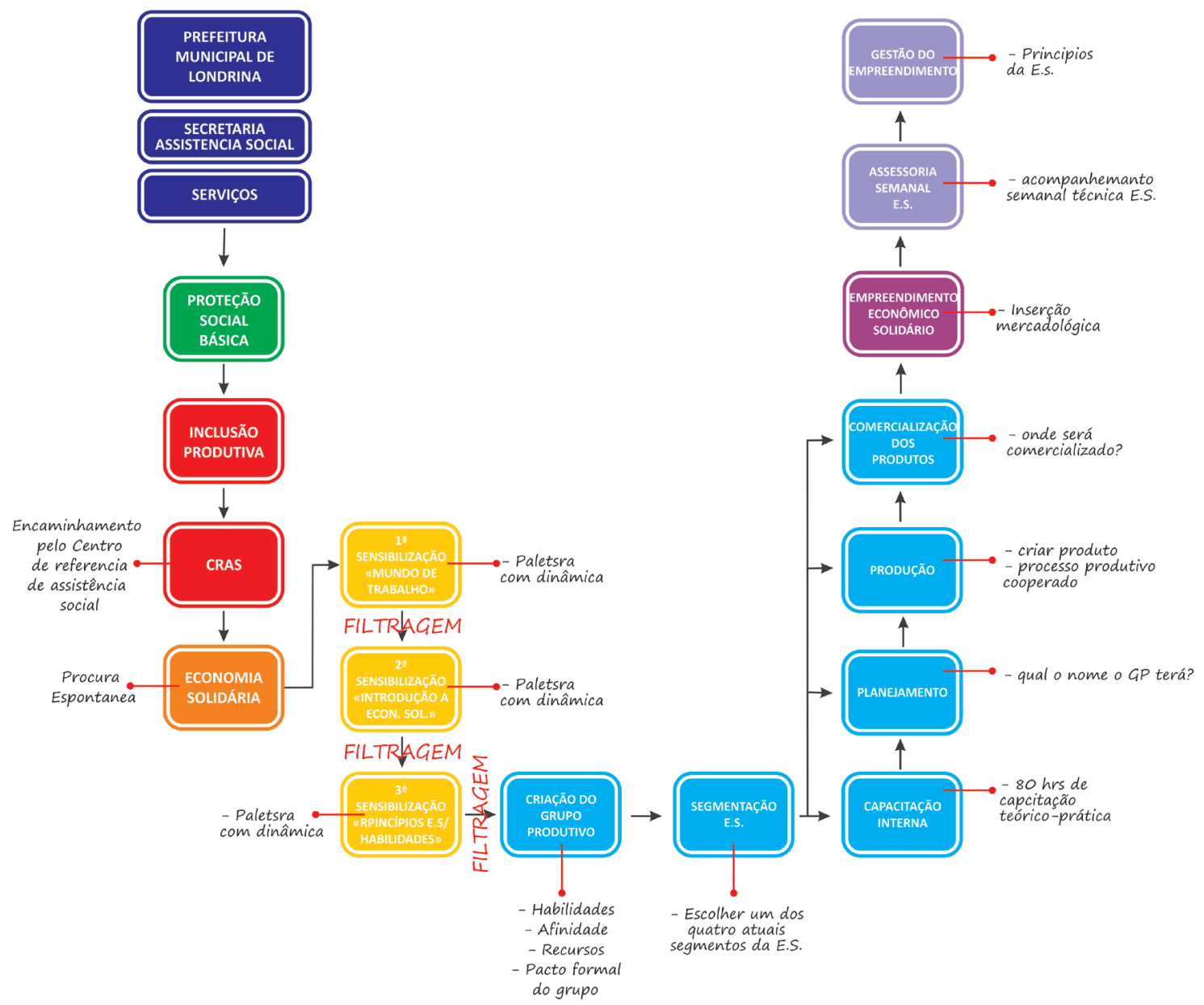

Fonte: própria, 2012.

A partir do fluxograma de processos, é possível visualizar o sistema e assim investigar cada etapa do processo a fim de inserir melhorias, que proporcionem compreensão e desempenho aos Grupos Produtivos com ações especificas em cada etapa, de acordo com as necessidades que poderão surgir na sequência do processo, amparadas e fundamentadas pela gestão de design que veremos a seguir.

Como resultados parciais esperados, desenvolveu-se uma lista de prioridades de design, as quais os Grupos Produtivos necessitam para que os mesmos consigam se organizar como uma empresa apresentar-se para o mercado e a seu consumidor de forma que eles consigam identificá-los e valorizálos.

Segue abaixo, quadro 02, a lista de prioridades que foi planejada a partir das entrevistas. Esta lista foi desenvolvida para os quatro segmentos mercadológicos do programa de Economia Solidária e que devem ser inseridos ao processo de gestão, para os novos grupos que se formarem no programa. 


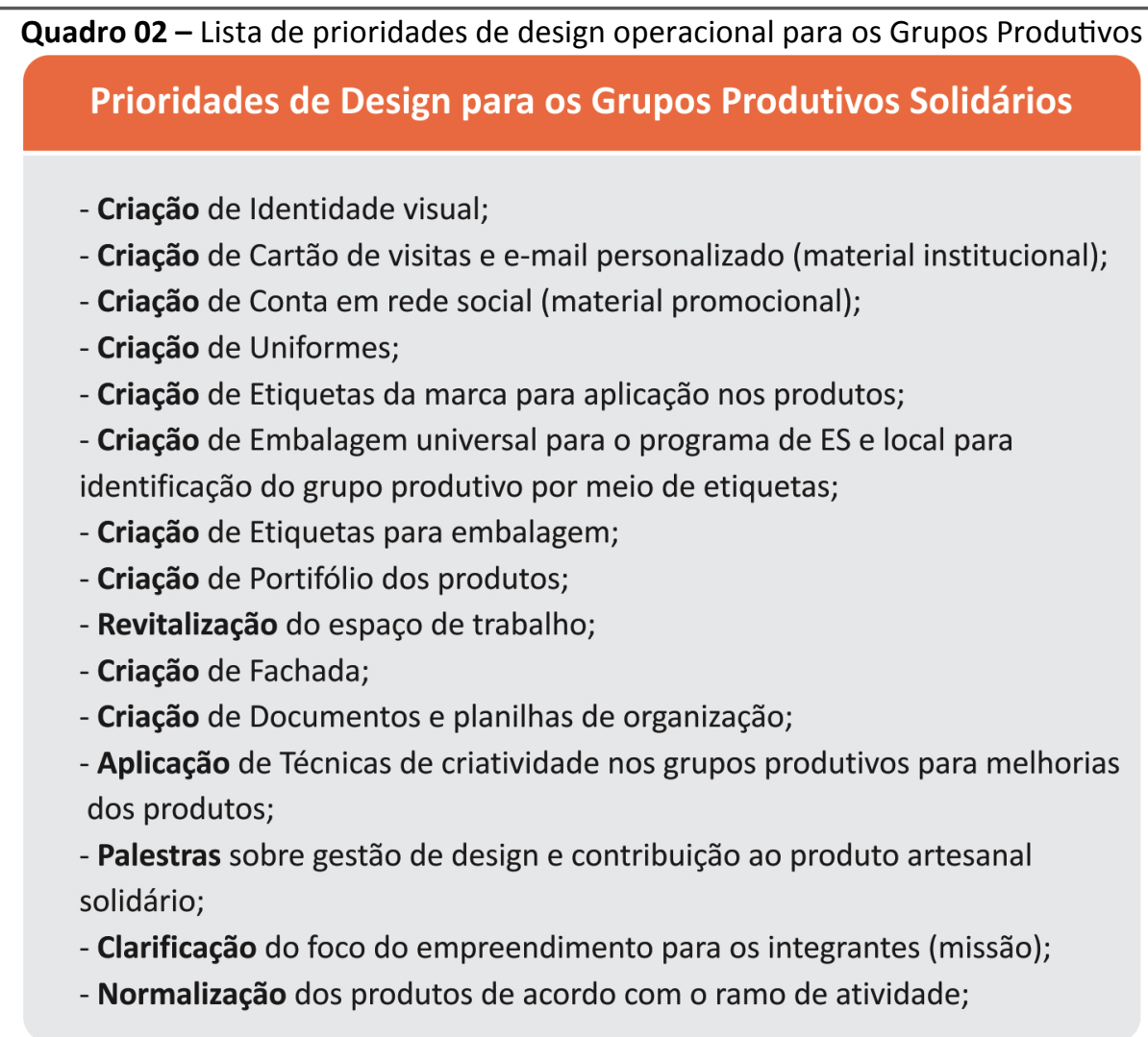

Fonte: própria, 2012.

A partir do quadro acima se deve criar para cada grupo produtivo, além de um nome, uma identidade visual para ser reconhecido visualmente e iniciar um relacionamento com seus clientes.

O cartão de visitas é a peça gráfica fundamental para os Grupos Produtivos, pois é uma forma de se apresentar e deixar um contato com alguma empresa ou interessado no produto com baixo custo.

A rede social atualmente é o meio de comunicação que está em destaque, pois todos estão conectados, consumindo informação e conteúdo. Inserir os Grupos Produtivos e o Programa Municipal de Economia Solidária neste novo canal de comunicação de importante, pois além de mostrar seu trabalho e marca para toda a rede, dissemina o que é a Economia Solidária proporcionando uma conscientização a sociedade.

Peças como etiquetas, embalagens e uniformes foram pensados como forma de organização do grupo para com os clientes, quanto à apresentação dos mesmos, desta forma o cliente passa a valorizálo criando hábitos de compra não só pessoal, mas para presentear outras pessoas, disseminando ainda mais o programa de Economia Solidária e incentivando o consumo consciente.

Os grupos devem ter portifólios atualizados, sejam estes físicos ou digitais para que possam mostrar aos interessados os seus produtos. Portfólio é uma forma de apresentação, além de levar ao cliente possibilidades e experiências de seu trabalho.

O próprio ambiente em que o Grupo Produtivo trabalha deve ter a identidade que ele esta construindo, sendo necessárias revitalizações para que o cliente possa sentir confiança no produto e desejo ao comprar um produto de um Grupo Solidário.

Os Grupos Produtivos necessitam de melhorarias em aspectos de organização, tais como: documentos e planilhas de organização interna.

Para tanto essas ações devem ser feitas com cuidado e devem ser acompanhadas diariamente tanto pelos gestores de design, quanto pelos Grupos Produtivos, aos quais devem ser oferecidas palestras e oficinas com temas de gestão, criatividade, comercialização e apresentação. 
Diante das prioridades de design é necessário apresentar a divisão de funcionamento entre seus níveis quando trabalhado com ações na gestão de design. Essa divisão contém aspectos que são essenciais para a organização e eficiência da autogestão e execução dos projetos de acordo com os princípios da Economia Solidária.

Segue abaixo o quadro com as divisões das ações até agora propostas.

Quadro 03 - Divisão das funções de cada Nível da gestão de design (operacional, tático e estratégico) de acordo com as prioridades de design para os Grupos Produtivos solidários.

\begin{tabular}{|c|c|c|}
\hline Gestão de Design Operacional & Gestão de Design Tática & Gestão de Design Estratégica \\
\hline $\begin{array}{l}\text { - Diagnostico inicial; } \\
\text { - Avaliar a natureza do projeto e a } \\
\text { capacidade da empresa } \\
\text { - Briefing } \\
\text { - Definir conceitos a serem } \\
\text { trabalhados; } \\
\text { - Gerenciar o orçamento; } \\
\text { - Gerenciar o grupo; } \\
\text { - Avaliar o projeto em seu final } \\
\text { deste, para as melhorias } \\
\text { contínuas. }\end{array}$ & $\begin{array}{l}\text { - Diagnostico inicial; } \\
\text { - Definir estratégia de produto; } \\
\text { - Mostrar como o design pode } \\
\text { - Desenvar; } \\
\text { informação; } \\
\text { - Desenvolver junto com o grupo o } \\
\text { conceito a ser trabalhado no } \\
\text { projeto; } \\
\text { - Definir orçamento; } \\
\text { - Organizar um processo para a } \\
\text { extensão de cada fase e os níveis } \\
\text { de decisão. } \\
\text { - Proceder à distribuição de } \\
\text { documentação e de reuniões; } \\
\text { - Estabelecer níveis de controle. } \\
\text { - Avaliar o processo para a } \\
\text { realização de melhorias } \\
\text { contínuas.final deste, para as } \\
\text { melhorias contínuas. }\end{array}$ & $\begin{array}{l}\text { - Diagnostico inicial; } \\
\text { - Diagnóstico da situação atual da } \\
\text { - Definir campos de atuação, } \\
\text { (tecnologia, produtos e mercado); } \\
\text { - Análise SWOT pontos fortes e } \\
\text { fracos, oportunidades e ameaças; } \\
\text { - Definir a imagem requerida; } \\
\text { - Identificar as necessidades dos } \\
\text { consumidores; } \\
\text { - Definir estratégias de design; } \\
\text { - Gerar conceitos; } \\
\text { - Gestão de recursos (criação de } \\
\text { conhecimento e formação de } \\
\text { - designer). } \\
\text { - Desenvolvimento de identidade; } \\
\text { - Definição de estratégia para a } \\
\text { - Avaliação } \\
\text { - Transformação em procedimentos } \\
\text { - Aprendizagem e re-inovação. }\end{array}$ \\
\hline
\end{tabular}

Fonte: adaptado de DEMARCHI (2011) apud MOZOTA (2003); BEST (2006); CELASCHI (2007); MANUAL DE GESTÃO DE DESIGN (1997); GIMENO (2000).

No nível operacional de forma concisa faz-se a execução dos projetos, porém este nível não funciona de forma eficaz sem pensar nas ações estratégicas e funcionais do projeto.

Já no nível tático, trabalha-se a utilização de recursos e funcionalidades, os quais dependem do nível estratégico e operacional para ter total desempenho. E da mesma forma o nível estratégico, depende do operacional e tático para sua totalidade de execução.

Portanto quando falamos em gestão de design, pensamos na relação desses níveis que se complementam para a eficiência do trabalho final.

Cada caso em particular deve ser pensado sobre a forma de apresentação em relação à gestão de design. No caso dos Grupos Produtivos foi utilizada como estratégia inicial a proposta de usar como ferramenta de organização o pensamento e método sistêmico para posteriormente a gestão de design planejar suas ações, como por exemplo, a apresentação de marca, para somente depois trabalhar outros aspectos, em nível estratégico e tático quanto o próprio operacional.

\section{Conclusão}

Neste artigo realizou-se uma pesquisa bibliográfica sobre a Economia Solidária e seus Grupos Produtivos, sobre o pensamento sistêmico e a sobre a gestão de design com foco em conceitos e nos níveis operacionais, tático e estratégico.

Por meio da técnica de entrevista de profundidade, obteve informações apresentadas por meio 
Preto, Seila Cibele Sitta; Figueiredo, Luiz Fernando Gonçalves de

de perfis, que resultou em um quadro final e lista de prioridades de design para os Grupos Produtivos da Economia Solidária.

Por meio de algumas etapas do método sistêmico foi construído um fluxograma de processos que se transformará por meios das relações e orientações em um mapa sistêmico para analisar o todo e detectar as partes que estão com dificuldades.

Para a lista de prioridades de design, foram considerados os pontos mínimos e necessários para a exposição dos Grupos Produtivos ao mercado de forma a serem identificados como uma empresa, com nome e marca incorporada aos seus produtos.

A lista de prioridades é interpretada e demonstrada pela abordagem de gestão de design, distribuindo as prioridades entre os três níveis, o operacional, o tático e o estratégico.

Portanto, ao pensar sistemicamente o processo de gestão torna-se complexo, pois é necessário pensar no todo para que as junções das partes se completem. Os três níveis da gestão de design, o estratégico, tático e operacional, o mapa sistêmico e mais a lista de prioridades formam um sistema, pois a partir deles existe uma entrada, processos e uma saída, para que haja um equlibrio e retroalimetação, segundo a teoria dos sistemas.

E considerando as características da Economia Solidária que aponta para uma nova lógica de desenvolvimento sustentável com geração de trabalho e distribuição de renda, mediante a um crescimento econômico, políticos e cultural, o pensamento sistêmico somado a gestão de design contribui como ferramenta organizacional além de proporcionar a valorização do produto, depois do processo pesquisado e sistematizado. Desta forma poderão ser feitas melhorias nos processos junto aos Grupos Produtivos, que além de alavancar esta Economia que ainda não é clara para a sociedade, resultando na sustentabilidade economica dos Grupos Produtivos e em sua geração de trabalho e renda.

\section{Notas}

${ }^{1}$ Indica nível mediano de equidade e justiça social. "Este índice analisa o desempenho de gestão e ações públicas, considerando três eixos principais: trabalho-renda, saúde e educação". (Política..., 2010:4).

${ }^{2}$ Política Municipal de Assistência Social.

${ }^{3}$ Ministério do Trabalho e Emprego.

${ }^{4}$ Ministério do Trabalho e Emprego. Disponível em http://www.mte.gov.br/EconomiaSolidária.oque.asp. Acesso em 24/10/2011.

${ }^{5}$ Programa de Economia Solidária. Disponível em http://EconomiaSolidária.londrina.pr.gov.br/quemsomos. aspx. Acesso em 24/11/2011.

${ }^{6}$ Secretaria Nacional de Economia Solidária.

${ }^{7}$ Ministério do Trabalho e Emprego. Disponível em http://www.mte.gov.br/ecoSolidária/secretaria_nacional_ apresentacao.asp. Acesso em 24/10/11).

${ }^{8}$ Vide Anexo.

${ }^{9}$ Poder Público Municipal.

\section{REFERÊNCIA}

ANDRADE, A.L.; SELEME, A.; RODRIGUES, L. H.; SOUTO, R. Pensamento Sistêmico: caderno de campo: o desafio da mudança sustentada nas organizações e na sociedade. Porto Alegre: Bookman, 2006.

ARROYO, J.C.T. Economia popular e Solidária: a alavanca para um desenvolvimento sustentável e solidário. 5. Ed. Petrópolis, RJ: Vozes, 2010. 
O pensamento sistêmico como ferramenta organizacional da gestão de design nos grupos produtivos ... solidários.

AVENDAÑO, Luiz E. C. Gestão do Design. Desine. N.3,out 2002. disponível em:

<http://www.dezine.com.br/zine/003/avendano_003.htm>. Acesso em mar 2003

BAHIANA, Carlos. A importância do Design para sua empresa. CNI, COMPI, SENAI/DR-RJ,

Brasília, DF. CNI 1998.

BERTALANFFY, L. von. Teoria Geral dos Sistemas: Fundamentos, desenvolvimento e aplicações. São Paulo: Editora Fundação Perseu Abramo, 2006.

CAPRA, F. O Ponto de Mutação - a ciência, a sociedade e a cultura emergente, Trad. Álvaro Cabral, São Paulo: Cultrix, 2006.

Centro Português de Design. Manual de Gestão do design. Portugal, 1997.

DEMARCHI, A. P. P. Gestão estratégica de design com a abordagem de design thinking: proposta de um sistema de produção do conhecimento. Tese de Doutoramento - Universidade Federal de Santa Catarina, Pós-Graduação em Engenharia e Gestão do Conhecimento, Florianópolis, 2011.

BAUER, M. W.; GASKELL, G. Pesquisa qualitativa com texto, imagem e som. Petrópolis: Vozes, 2003.

GIMENO, J. M. I. La gestión Del diseño en la empresa. Madrid: McGraw-Hill, 2000

MARTINS, R. F. F.; MERINO, E. A. D. A Gestão de Design como Estratégia Organizacional. Rosane Fonseca de Freitas, Eugenio Andrés Diáz Merino. 2. Ed. - Londrina: EDUEL; Rio de Janeiro: Rio Books, 2011. 244p.

MARTINS, G. de A. \& THEÓPHILO, C. R. Metodologia da Investigação Científica para Ciências Sociais Aplicadas, São Paulo: Atlas, 2009.

MOZOTA, B. B.de. Gestão do Design: usando o design para construir valor na marca e inovação corporativa. Porto Alegre. Bookman, 2011.

SANTOS, G. F. dos. Negócios Sustentáveis e Desenvolvimento - Uma relação de causa e efeito, organizado por Rocha, M.T., Dorresteijn, H. \& Gontijo M.J. Empreendedorismo em Negócios Sustentáveis - plano de negócios como ferramenta de desenvolvimento, São Paulo: Petrópolis; Brasília, DF: IEB - Instituto Internacional de Educação do Brasil, 2005.

SOARES, Valdir Ferreira. UFRJ. Escola de Belas Artes. Curso de Desenho Industrial. Rio de janeiro. Disponível em:< http://www.eba.ufrj.br/aula/gp/>. Acesso em: jan 2002.

WOLF, Brigite. O Design Management como fator de sucesso comercial. Florianópolis:

FIESC/IEL, ABIPTI, Programa Catarinense de Design, SEBRAE, CNPq, 1998.

Programa de Economia Solidária. <http://www.mte.gov.br/EconomiaSolidária.oque.asp>. Acesso em 24/10/11.

<http://EconomiaSolidária.londrina.pr.gov.br/quemsomos.aspx>. Acesso em 24/10/11.

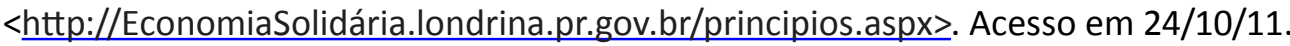

<http://EconomiaSolidária.londrina.pr.gov.br/projetos.aspx>. Acesso em 24/10/11.

Ministério do Trablho e Emprego. <http://www.mte.gov.br/EconomiaSolidária.oque.asp>. Acesso em 24/10/11. 
Preto, Seila Cibele Sitta; Figueiredo, Luiz Fernando Gonçalves de <http://www.mte.gov.br/ecoSolidária/secretaria nacional apresentacao.asp>. Acesso em 24/10/11.

LEI No 10.523, DE 28 DE AGOSTO DE 2008. <http://EconomiaSolidária.londrina.pr.gov.br/Lei.aspx>. Acesso em 24/10/11. 